\title{
Synthesis and Characterization of Fe, Ru and Os Metal Borides
}

\section{Omar Ali Al-Zain* and Al-Masoudi Reem Soliyman}

Chemistry Department, Faculty of Science, King Abdulaziz University, Jiddah, Saudi Arabia

\begin{abstract}
Direct reaction of $\mathrm{Fe}_{2} \mathrm{O}_{3}$ at 500,700 and $1000^{\circ} \mathrm{C}$ for two, two and 15 hours, respectively, with elemental boron in a muffle furnace yielding black beautiful nanorods of FeB crystals with high yield of $72 \%$ (as proved by xrd, tem and Magnetic hysteresis). Going down the group of the transition metals $\mathrm{RuCl}_{3}$ and $\mathrm{OsCl}_{3}$ reacted directly with elemental boron in a muffle furnace at 500,700 and $1000^{\circ} \mathrm{C}$ for two, two and 15 hours, respectively yielding nanorods crystals (as proved by $x r d$, tem and Magnetic hysteresis) of $\mathrm{RuB}_{2}, \mathrm{Ru}_{2} \mathrm{~B}_{3}$ (yield was 68\%) and OsB $\mathrm{B}_{2}$ (yield was $56 \%$ ).
\end{abstract}

Keywords: Nanocomponds; Metal borides; Nanowires; Nanocrystals

\section{Introduction}

Boron is used for over 200 inorganic compounds, especially metal borides. Metal borides, which are formed by transition metals or alkaline earth metals, are indispensable materials to develop electronic or nano-ordered devices, because they are mechanically hard materials with high melting points and good corrosion resistance [1].

Metal borides stay mostly uncommon for chemists, in spite of a specific set of very good properties as semiconductors and catalysts, but also with bulk boride noncompliant conductive ceramics, hard magnets, superconductors, and hard materials that already supplied the worldwide industrial market with phosphide. Fundamental property aspects of bulk metal borides and metal phosphides are also the focus of many researchers: conduction, luminescence, field emission [2]. Thermoelectric [3] and magnetic [4] properties, ultra-hardness [5] and behaviors as diffusion barriers. Iron boride is attractive because of the magnetic properties and catalytic properties [6]. The development of iron boride change coatings on ferrous substrates is alluring for an extensive variety of applications $[7,8]$.

Iron boride transformation coatings can be synthesized in numerous ways, including molten salt boron izing, gas boron izing, with and without electrolysis $[9,10]$. In the Ru-B system, RuB, RuB $\mathrm{Ru}_{7} \mathrm{~B}_{3}$ and $\mathrm{Ru}_{2} \mathrm{~B}_{3}$ were acquired experimentally [11-13]. Recently, OsB was prepared at ambient conditions [14] and the consolidation of boron into the osmium lattice gives rise to a significant enhancement of the hardness. The blend of discernible mechanical properties and the low-cost prepare condition recommends that $\mathrm{Ru}$ and Os borides might be good candidates for hard materials. Addition of more boron reinforces the mechanical properties of metal borides.

In an effort to find a better synthetic rout to produce nanocrystals of metal borides. We are reporting here the synthesis and characterization of $\mathrm{Fe}, \mathrm{Ru}$ and Os Metal Borides following our previous publications in this journal $[15,16]$

\section{Experimentation/Empirical Analysis}

\section{Reagents}

Unless otherwise specified, reagent grade chemicals were employed. The precursor materials were Iron Oxide $\left(\mathrm{Fe}_{2} \mathrm{O}_{3}\right.$, SigmaAldrich), Ruthenium (III) Chloride $\left(\mathrm{RuCl}_{3}, 36-40 \% \mathrm{Ru}\right.$ ACROS Organic), Osmium (III) Chloride ( $\mathrm{OsCl}_{3}$, ACROS Organic). Boron Powder (Amorphous) (B, Loba Chemie). Hydrochloric acid ( $\mathrm{HCl}$, Sigma-Aldrich, fuming $>37 \%)$.

The Powder X-ray diffraction (XRD) measurement was carried out with a Bruker D8 Advance diffractometer (CuKa $\lambda=1.54 \AA$; Ni filter; 40 $\mathrm{KV}, 40 \mathrm{~mA}$; Divergence slit: $1 \mathrm{~mm}$, LynxEye one-dimensional detector, Detector slit: $8 \mathrm{~mm}$ ). Scanning Electron Microscope and Transmission Electron Microscope (SEM and TEM) were performed by employing a microscope of model Titan 80-300 CT from FEI Company (Hillsboro, OR), which was equipped with a field emission gun (FEG) and a charged-Couple Devices (CCD) camera of $4 \mathrm{k} x$ 4k pixels. Furthermore, the analyses of all samples were performed by operating the microscope at $300 \mathrm{kV}$ accelerating voltage in order to take full advantage of the highest spatial resolution possible from this microscope. An aperture of 100 microns was also inserted into the back-focal plane (BPF) of the objective lens, to improve the image contrast. The Magnetization measurement was carried out in an ever-cool Squid-Vibrating Sample Magnetometer (SVSM), from the manufacturer Quantum Design, USA.

\section{Synthesis}

Preparation of metal borides using metal oxide and boron powder

Iron boride: $7.9844 \mathrm{~g}$ of Iron (III) Oxide (50 mmol) and 10.811 g Amorphous Boron Powder $(250 \mathrm{mmol})$, were mixed in a porcelain crucible and placed in a muffle furnace. Temperature gradually raised starting $500^{\circ} \mathrm{C}$ for two hours then $700^{\circ} \mathrm{C}$ for two hours and finally $1000^{\circ} \mathrm{C}$ for 15 hours. After cooling to the room temperature in a muffle furnace, the mixture was leached with $1 \mathrm{~N} \mathrm{HCl}$ at $100^{\circ} \mathrm{C}$ for three hour under magnetic stirring. Solution was filtered and washed with distilled water and ethanol. The precipitate was then treated with $1 \mathrm{~N} \mathrm{NH}_{4} \mathrm{Cl}$ at $100^{\circ} \mathrm{C}$ for three hour under magnetic stirring. Solution was filtered and washed with distilled water and ethanol and dried in a vacuum oven at $150^{\circ} \mathrm{C}$ for 3 hours. The yield is $72 \%$.

$$
\mathrm{Fe}_{2} \mathrm{O}_{3}+4 \mathrm{~B} \underset{500-1000^{\circ} \mathrm{C}}{\longrightarrow} 2 \mathrm{FeB}+\mathrm{B}_{2} \mathrm{O}_{3}
$$

*Corresponding author: Omar Ali Al-Zain, Chemistry Department, Faculty of Science, King Abdulaziz University, Jiddah, Saudi Arabia, Tel: 966555600872 E-mail: alzain2005@yahoo.com

Received: October 11, 2017; Accepted: October 20, 2017; Published: Octobe 28, 2017

Citation: Al-Zain OA, Soliyman AMR (2017) Synthesis and Characterization of $\mathrm{Fe}$ Ru and Os Metal Borides. J Nanomed Nanotechnol 8: 469. doi: 10.4172/21577439.1000469

Copyright: (c) 2017 Al-Zain OA, et al. This is an open-access article distributed under the terms of the Creative Commons Attribution License, which permits unrestricted use, distribution, and reproduction in any medium, provided the original author and source are credited. 


\section{Preparation of metal borides using metal chlorides and boron powder}

Ruthenium boride: $0.6223 \mathrm{~g}$ of Ruthenium (III) Chloride ( $1 \mathrm{mmol})$ and $0.8649 \mathrm{~g}$ Amorphous Boron Powder $(10 \mathrm{mmol})$, were mixed in a porcelain crucible and placed in a muffle furnace. Temperature gradually raised starting $500^{\circ} \mathrm{C}$ for two hours then $700^{\circ} \mathrm{C}$ for two hours and finally $1000^{\circ} \mathrm{C}$ for 15 hours. After cooling to the room temperature in a muffle furnace, the mixture was leached with $1 \mathrm{~N} \mathrm{HCl}$ at $100^{\circ} \mathrm{C}$ for three hour under magnetic stirring. Solution was filtered and washed with distilled water and ethanol. The precipitate was then treated with $1 \mathrm{~N} \mathrm{NH}_{4} \mathrm{Cl}$ at $100^{\circ} \mathrm{C}$ for three hour under magnetic stirring. Solution was filtered and washed with distilled water and ethanol and dried in a vacuum oven at $150^{\circ} \mathrm{C}$ for 3 hours. The yield is $68 \%$.

$$
3 \mathrm{RuCl}_{3}+8 \mathrm{~B} \underset{500-1000^{\circ} \mathrm{C}}{\stackrel{\Delta}{\longrightarrow}} \mathrm{RuB}_{2}+\mathrm{Ru}_{2} \mathrm{~B}_{3}+3 \mathrm{BCl}_{3}
$$

\section{Osmium boride}

$0.5932 \mathrm{~g}$ of Osmium (III) Chloride $(2 \mathrm{mmol})$ and $0.6487 \mathrm{~g}$ Amorphous Boron Powder $(20 \mathrm{mmol})$, were mixed in a porcelain crucible and placed in a muffle furnace. Temperature gradually raised starting $500^{\circ} \mathrm{C}$ for two hours then $700^{\circ} \mathrm{C}$ for two hours and finally $1000^{\circ} \mathrm{C}$ for 15 hours. After cooling to the room temperature in a muffle furnace, the mixture was leached with $1 \mathrm{~N} \mathrm{HCl}$ at $100^{\circ} \mathrm{C}$ for three hour under magnetic stirring. Solution was filtered and washed with distilled water and ethanol. The precipitate was then treated with $1 \mathrm{~N} \mathrm{NH}_{4} \mathrm{Cl}$ at $100^{\circ} \mathrm{C}$ for three hour under magnetic stirring. Solution was filtered and washed with distilled water and ethanol and dried in a vacuum oven at $150^{\circ} \mathrm{C}$ for 3 hours. The yield is $56 \%$.

$$
\mathrm{OsCl}_{3}+3 \mathrm{~B} \underset{500-1000^{\circ} \mathrm{C}}{\stackrel{\Delta}{\longrightarrow}} \mathrm{OsB}_{2}+\mathrm{BCl}_{3}
$$

\section{Results and Discussion}

Two different preparation methods in the solid phase were applied, metal oxide and metal chloride mixed with elemental boron in muffle furnace.
Iron oxide, $\mathrm{Fe}_{2} \mathrm{O}_{3}$, and elemental boron were reacted in a muffle furnace at $1000^{\circ} \mathrm{C}$ for 15 hours under argon atmosphere. Leaching, filtering and drying the product yielding beautiful black crystals of $\mathrm{FeB}$ as it could be seen in XRD (Figure 1a). TEM (Figure 1b) clearly shows nanocrystals and nanorods. Magnetic hysteresis of FeB reflects superparamagnetic properties [17] which indicates the nanosystem (Figure 1c).

Going down group eight (VIIIB) Ruthenium chloride, $\mathrm{RuCl}_{3}$, reacts with elemental boron in muffle furnace at $1000^{\circ} \mathrm{C}$ for 15 hours under a blanket of argon. Leaching, filtering and drying the product yielding beautiful black nanorods crystal mixture of $\mathrm{RuB}_{2}$ and $\mathrm{Ru}_{2} \mathrm{~B}_{3}$ as it could be seen in XRD (Figure 2a). TEM (Figure 2b) clearly shows nano and nanorod crystals. Magnetic hysteresis of the product of $\mathrm{RuB}_{2}$ and $\mathrm{Ru}_{2} \mathrm{~B}_{3}$ reflects superparamagnetic properties (Figure 2c).

Similarly Osmium chloride, $\mathrm{OsCl}_{3}$, reacted with elemental boron in muffle furnace at $1000^{\circ} \mathrm{C}$ for 15 hours under a blanket of argon. Leaching, filtering and drying the product yielding beautiful black nanorod crystals of $\mathrm{OsB}_{2}$ as it could be seen in XRD pattern (Figure 3a). SEM (Figure 3b) shows a homogenous cluster of crystals. TEM (Figure 3c) shows nano crystals and nanorod. Magnetic hysteresis of the, $\mathrm{OsB}_{2}$, product indicates superparamagnetic properties (Figure 3d).

\section{Conclusion}

Direct reaction of iron oxide and ruthenium and osmium chlorides with elemental boron produced a nanocrystals and nanorods of metal borides, Solid phase reaction of group eight (XIII) proved that first, second and third rows transition metals work very well. Very encouraging results where the yields were 72,68 and $56 \%$ for iron, ruthenium and osmium respectively. High purity was obvious from XRD patterns. TEM and magnetic hysteresis superparamagnetism clearly prove nanocrystals and nanorods.

In previous work of group $\mathrm{V}(\mathrm{V}, \mathrm{Nb}$ and $\mathrm{Ta})[15]$ and group $\mathrm{XI}(\mathrm{Cr}$, Mo and W) [16] solid phase worked fine with second and third rows of transition metals, while in case of group XIII (Fe, Ru and Os) solid phase worked fine with first, second and third rows of transition metals

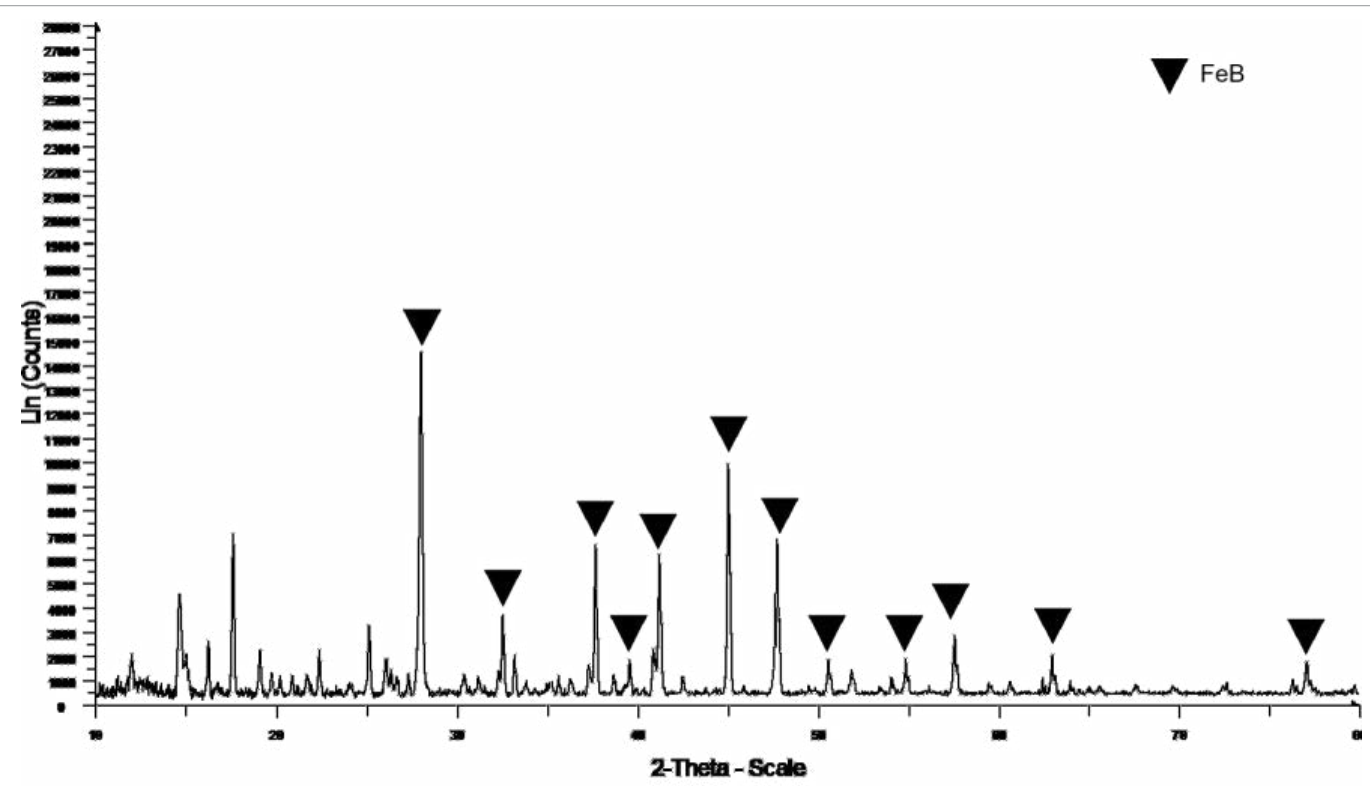

Figure 1a: XRD spectra of $\mathrm{FeB}$ produced by direct reaction of $\mathrm{Fe}_{2} \mathrm{O}_{3}$ and $\mathrm{B}$. 


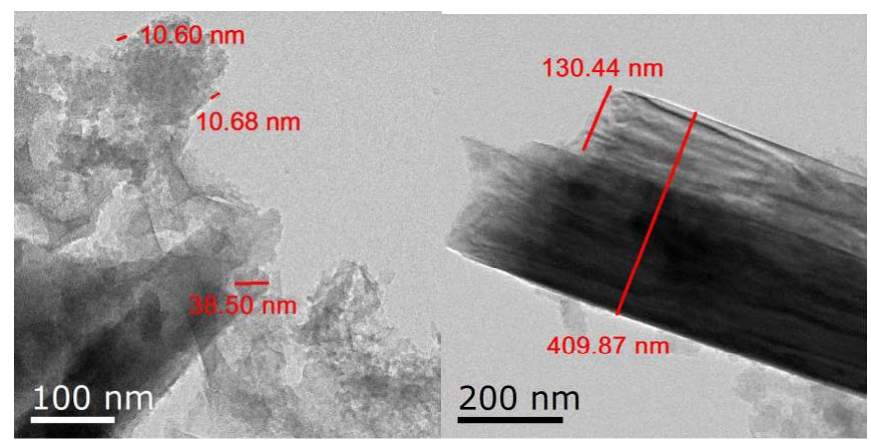

Figure 1b: TEM image of beautiful nanorods crystals FeB.

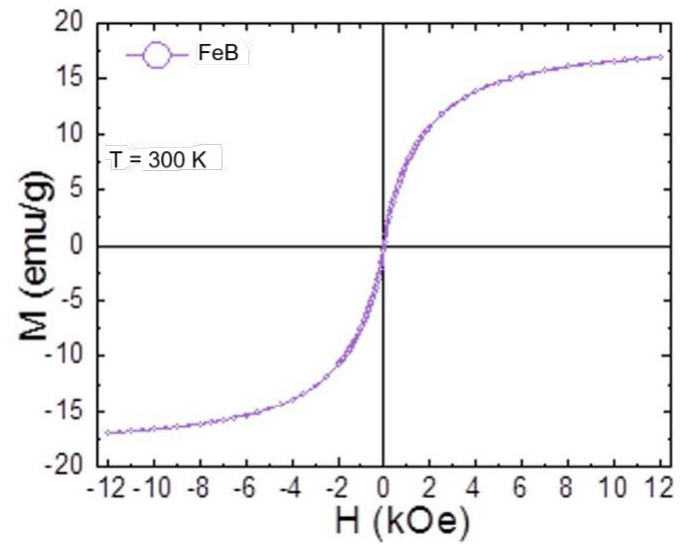

Figure 1c: Magnetic hysteresis superparamagnetism of FeB.

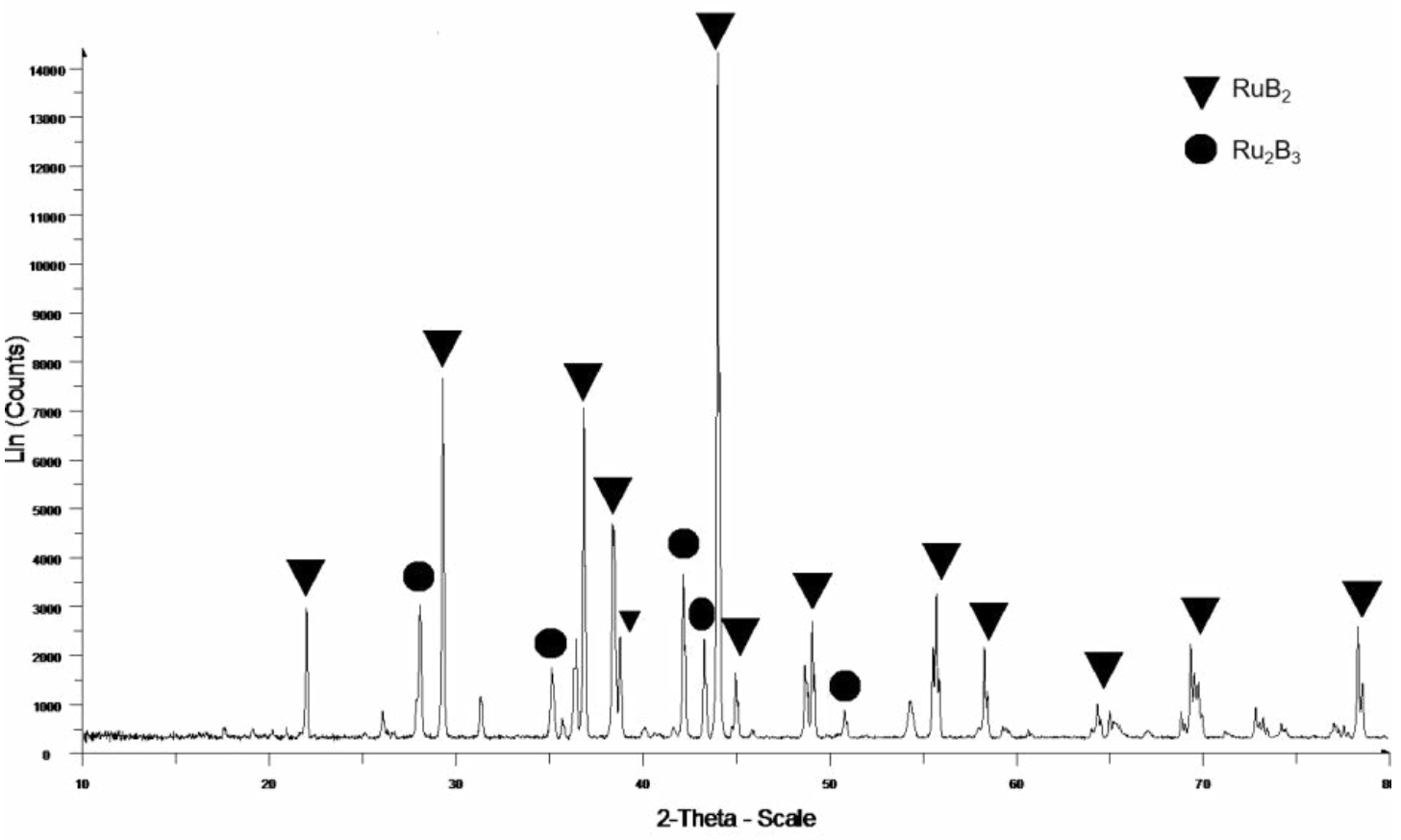

Figure 2a: XRD spectra of black crystals of $\mathrm{RuB}_{2}$ and $\mathrm{Ru}_{2} \mathrm{~B}_{3}$ produced by direct reaction of $\mathrm{RuCl}_{3}$ and $\mathrm{B}$. 


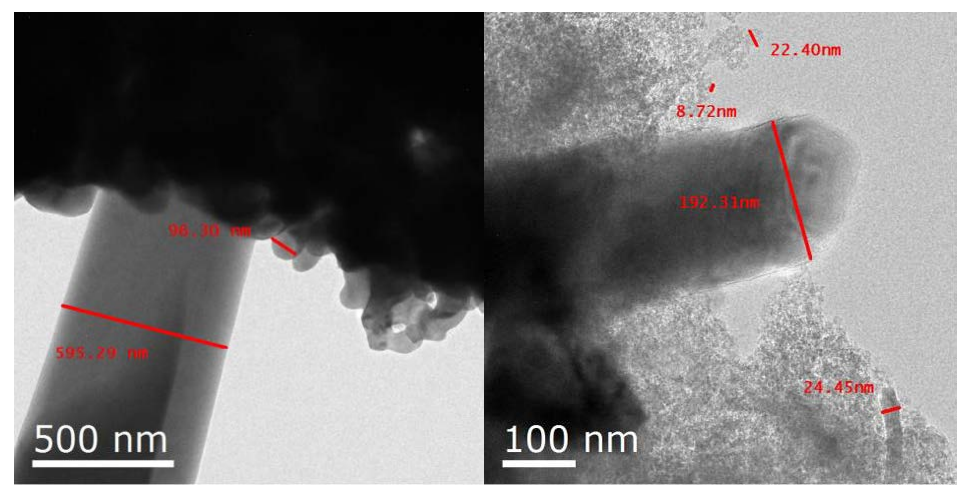

Figure $2 \mathrm{~b}$ : TEM image of nanorods crystals of $\mathrm{RuB}_{2}$ and $\mathrm{Ru}_{2} \mathrm{~B}_{3}$.

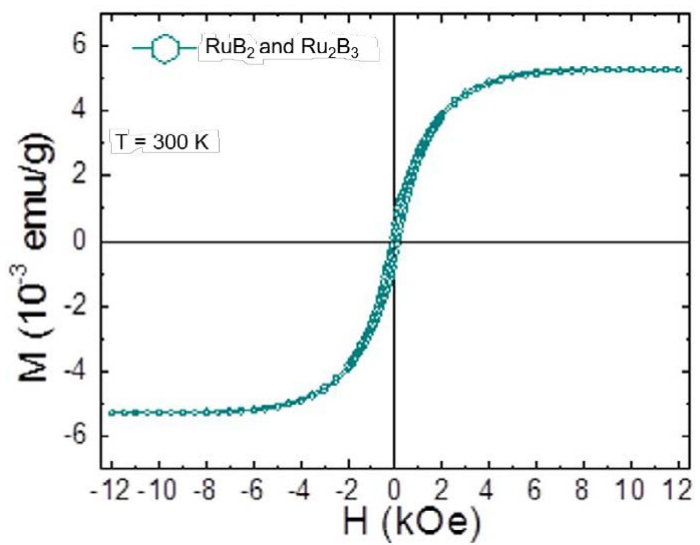

Figure 2c: Magnetic hysteresis shows superparamagnetism of $\mathrm{RuB}_{2}$ and $\mathrm{Ru}_{2} \mathrm{~B}_{3}$ nanorods

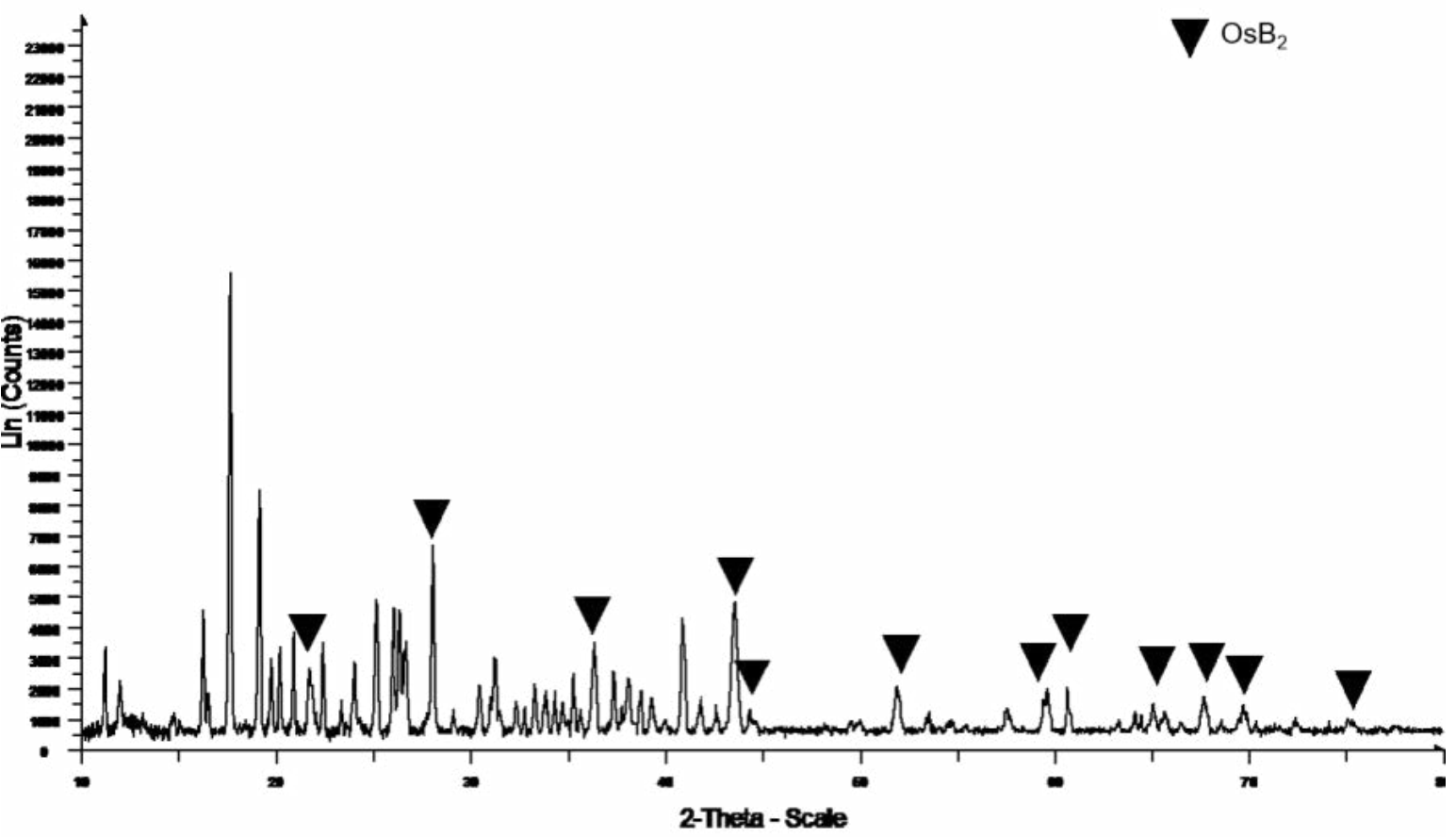

Figure 3a: XRD pattern of $\mathrm{OsB}_{2}$ yielded by reaction of $\mathrm{OsCl}_{3}$ with $\mathrm{B}$. 
Citation: Al-Zain OA, Soliyman AMR (2017) Synthesis and Characterization of Fe, Ru and Os Metal Borides.J Nanomed Nanotechnol 8: 469. doi: 10.4172/2157-7439.1000469

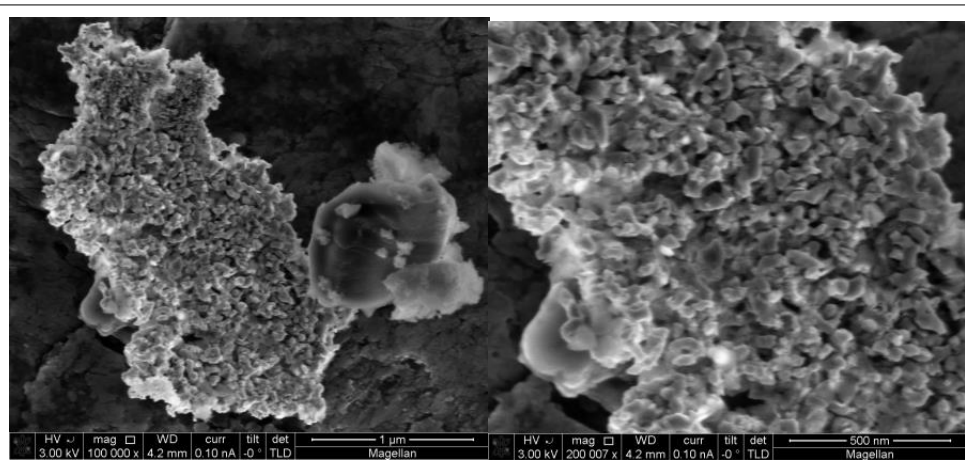

Figure 3b: SEM image of crystals of $\mathrm{OsB}_{2}$

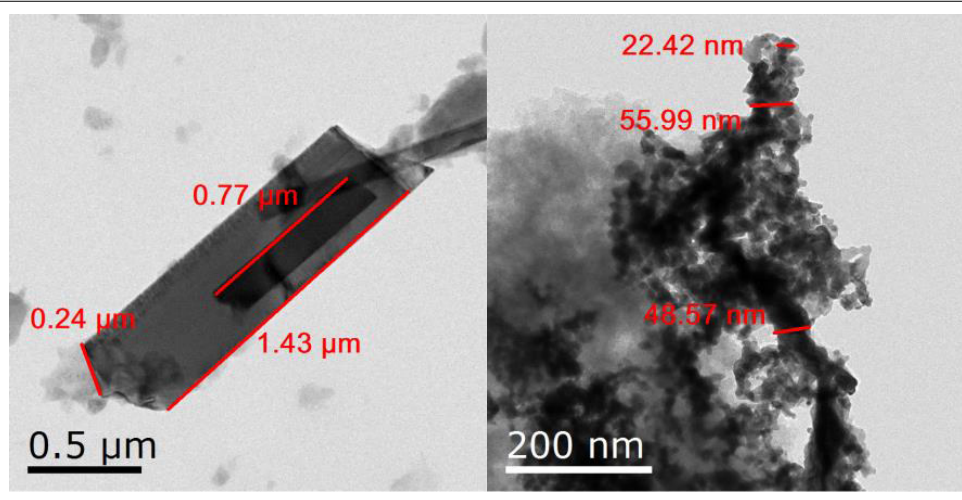

Figure 3c: TEM image of nanorod crystals of $\mathrm{OsB}_{2}$.

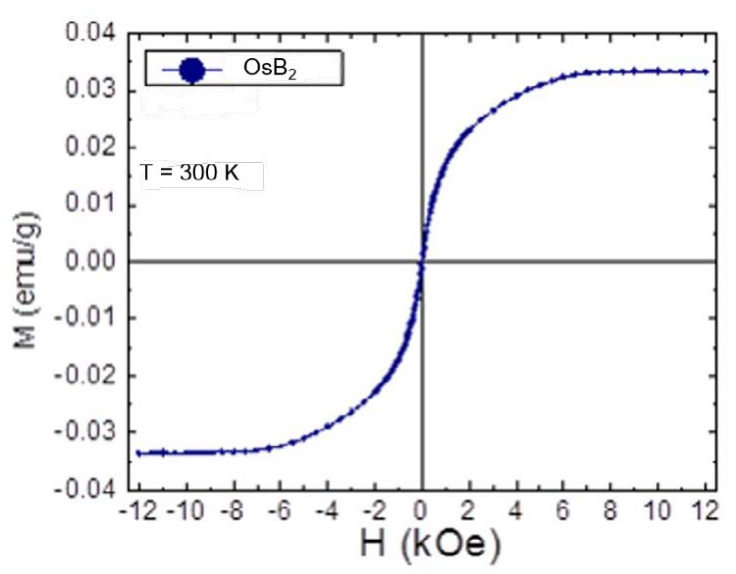

Figure 3d: Magnetic hysteresis superparamagnetism of $\mathrm{OsB}_{2}$.

\section{Acknowledgment}

Authors would like to express gratitude and appreciation to King Abdulaziz City for Science and Technology for providing the research Grant AT-34-255. Authors would also like to express thanks to King Abdulaziz University and in particular, the chemistry department for their continuous support.

\section{References}

1. Munro RG (2000) Material properties of titanium diboride. Journal of Research of the National Institute of Standards and Technology 105: 709.

2. Ji X, Zhang Q, Xu J, Zhao Y (2011) Rare-earth hexaborides nanostructures: recent advances in materials, characterization and investigations of physical properties. Progress in Solid State Chemistry 39: 51-69.
3. Mori T (2009) Novel physical properties of rare earth higher borides. Journal of Physics: Conference Series.

4. Levine JB, Tolbert SH, Kaner RB (2009) Advancements in the Search for Superhard Ultra-Incompressible Metal Borides. Advanced Functional Materials 19: 3519-3533.

5. Schneider SB, Baumann D, Salamat A, Konôpková Z, Liermann H, et al. (2012) Materials properties of ultra-Incompressible $\mathrm{Re}_{2} \mathrm{P}$. Chemistry of Materials 24 : 3240-3246.

6. Rades S, Kornowski A, Weller H, Albert B (2011) Wet-Chemical Synthesis of Nanoscale Iron Boride, Xafs Analysis and Crystallisation to $\alpha-F e B$. ChemPhysChem 12: 1756-1760.

7. Samsonov G, Kunitsky Y (1972) Resistivity of Fe, Co and Ni Borides. Phys Me Metallogr 33: 216-219. 
Citation: Al-Zain OA, Soliyman AMR (2017) Synthesis and Characterization of Fe, Ru and Os Metal Borides.J Nanomed Nanotechnol 8: 469. doi:

8. Kostetsky I, Lvov S, Kunitsky Y (1971) Some physical properties of iron borides Izvest Akad Nauk Sssr NEORG Materialy 7: 951-955.

9. Thompson R (1965) Borides: Their Chemistry and Applications. (Royal Institute of Chemistry).

10. Biddulph R (1977) Boronizing for erosion resistance. Thin Solid Films 45: 341 347.

11. Gu Q, Krauss G, Steurer W (2008) Transition Metal Borides: Superhard versus Ultra-incompressible. Advanced materials 20: 3620-3626.

12. Fokwa BP, Misse PR, Gilleben M, Dronskowski R (2010) Sn-flux syntheses, characterizations and bonding analyses of OsB and TiB2. Journal of Alloys and Compounds 489: 339-342.
13. Aronsson B, Sullivan J, Zackrisson M, Andersson G, Stenhagen E, et al. (1959) The crystal structure of Ru7B3. Acta Chemica Scandinavica 13: 109.

14. Cumberland RW, Weinberger MB, Gilman JJ, Clark SM, Tolbert SH, et al (2005) Osmium diboride, an ultra-incompressible, hard material. Journal of the American Chemical Society 127: 7264-7265

15. Al-Zain OA, Al-Masoudi RS (2017) Solid and Liquid Synthetic Routes of Vanadium, Niobium and Titanium Nano-metal Borides. J Nanomed Nanotechnol 8: 466 .

16. Al-Zain OA, Al-Masoudi RS (2017) Different Synthetic Routes of Group Six (VIB) Nano-Metal Borides. J Nanomed Nanotechnol 8: 464.

17. Gittleman JI, Abeles B, Bozowski S (1974) Superparamagnetism and relaxation effects in granular $\mathrm{Ni}_{-} \mathrm{SiO}_{2}$ and $\mathrm{Ni}-\mathrm{Al}_{2} \mathrm{O}_{3}$ films. Physical Review B 9: 3891-3897. 